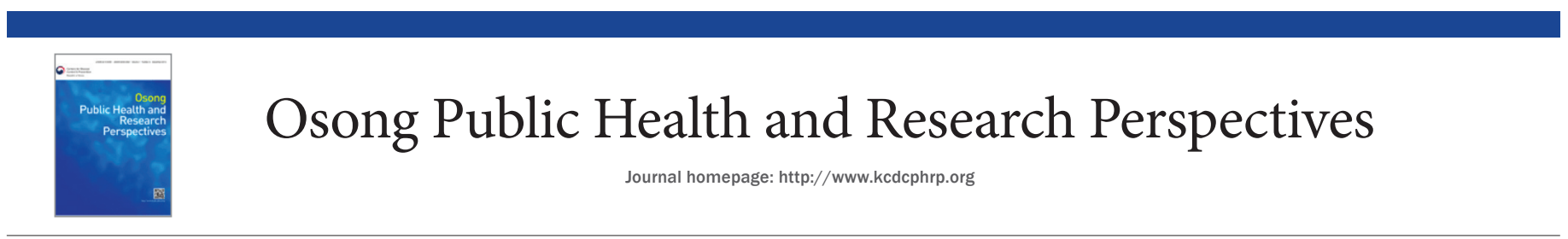

Editorial

\title{
Towards a Smoke-Free Society
}

\author{
Hae-Wol Cho a,b,* \\ a Osong Public Health and Research Perspectives, Korea Centers for Disease Control and Prevention, Cheongju, Korea \\ ${ }^{b}$ College of Medicine, Eulji University, Daejeon, Korea
}

https://doi.org/10.24171/j.phrp.2018.9.5.01 pISSN 2210-9099 elSSN 2233-6052
Smoking is a leading cause of cardiovascular diseases and cancers such as pulmonary, laryngeal, esophageal, oral, and bladder cancer [1]. The number of deaths attributed to smoking was reported to be approximately 6 million worldwide in 2015, and is expected to rise each year, reaching a predicted 8 million by 2030 [2]. The 2015 National Health and Nutrition Examination Survey of the Republic of Korea showed that the average smoking rate was $22.6 \%$, with the smoking rate of males reported at $39.3 \%$ and that of females at 5.5\% [3]. The smoking population of the Republic of Korea aged 15 and over in 2014 was $20.0 \%$, which was slightly higher than the OECD average (18.9\%) [4]. The World Bank predicted that approximately 500 million smokers will die from smokingrelated causes if the current smoking trends continue [5]. Half of these smokers are children (12 years and under) or teenagers (13-19 years). In light of the continued rise in teenage smoking in the Republic of Korea and the gradual lowering of the age at which smoking begins, a solution to address these issues is necessary [6].

The goal of the Republic of Korea's smoking cessation policy is to prevent smoking, encourage smoking cessation, and create a non-smoking environment to protect non-smokers [7]. The enactment of the National Health Promotion Act in 1995 enabled regulation of cigarette smoking. Further traction for smoking cessation policies was gained following the signing of the WHO Framework Convention on Tobacco Control on July 21, 2003, which was ratified on May 16, 2005 [8]. A number of smoking cessation support programs has been followed, such as smoking cessation clinics in public health centers, telephone counseling, and programs to encourage smoking cessation amongst military personnel, riot police and conscripted policemen have been followed since 2005 . These programs have resulted in a $36.2 \%$ smoking cessation success rate in 2005. This success rate has consistently improved annually reaching $46.5 \%$ in 2008 [9]. However, beyond 2010 the success rate plateaued at approximately $40 \%$. Furthermore, there were no notable smoking cessation policies introduced to address this issue and specifically target groups where there was an increase in smoking (women and teenagers). Therefore, a new smoking cessation policy was necessary. In 2015, the Ministry of Health and Welfare established 18 Tobacco Control Centers to run programs primarily for women, teenagers (not under school supervision), college students, and heavy smokers. Regional Tobacco Control Centers considered these groups key and provided 'on-call smoking cessation support services' and operated 'smoking cessation programs' [10]. Despite this targeted intervention, program effects have seldom been pursued.

In the current issue of Osong Public Health and Research Perspectives, Yeom et al [11] aimed to identify the criteria for developing a successful smoking cessation program through the National Tobacco Control Center. This study examined the smoking behaviors and the factors that affected smoking cessation success rates amongst individuals registered in the intensive care smoking cessation camps of the Tobacco Control Center. Heavy smokers enrolled in the program were classified into a success $(n=69)$ or a failure group $(n=29)$ according to whether they had maintained smoking cessation for 6 months after the program had finished. The individuals' demographics, smoking behavior, and smoking cessation-

* Corresponding author: Hae-Wol Cho

College of Medicine, Eulji University, Daejeon, Korea

E-mail: hwcho@eulji.ac.kr

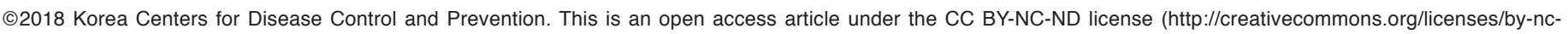
nd/4.0/). 
related characteristics were compared.

Yeom et al [11] found that significantly more participants in the success group had a spouse (98.6\%) compared with participants in the failure group (82.8\%). Also, a significant difference in the frequency of counseling sessions between the success and failure groups was reported. Of those individuals who received counseling 3-5 times during the treatment period, $72.5 \%$ quit smoking successfully, indicating that those who received more counseling had a higher likelihood of smoking cessation success. Furthermore, the higher the level of education, the higher the success rate.

Yeom et al [11] suggested that a cooperative system of supportive services for community-based smoking cessation would be needed to develop effective smoking cessation programs that considered regional characteristics to find applicable measures.

\section{Conflicts of Interest}

The author declared no conflicts of interest.

\section{References}

[1] Burns DM. Nicotine Addiction in: Harrison's principal of internal medicine, 16th ed. New York (NY): McGraw Hill; 2015. p. 2573-6.

[2] Mackay JL, Erikson M, Ross H. The Tobacco atlas, 4th ed. Atlanta (GA): The American Cancer Society Inc.; 2012. p. 16-7.

[3] Ministry of Health and Welfare, Korea Centers for Disease Control and Prevention [Internet]. Korea Health statistics 2015: Korea National Health and Nutrition Examination Survey (KNHANES VI-3). Cheongju (Korea): Korea Centers for Disease Control and Prevention; 2015 [cited 2017 Mar 1]. Available from: http://knhanes.cdc.go.kr/knhanes/.

[4] National Cancer Center [Internet]. No smoke guide. Goyang (Korea): National Cancer Center; 2017 [cited 2017 Mar 1]. Available from: http:// www.nosmokeguide.or.kr/nosmokeguide/.

[5] The World Bank. Curbing the Epidemic Governments and the Economics of Tobacco Control. Tobacco Control 1999;8(2):196-201.

[6] Kam S, Lee KH, Park KS, et al. Smoking and Alcohol Abuse Status and Its Related Factors of Middle and High School Students in Taegu City. J Korea Soc Matern Child Health 2000;4(2):233-53.

[7] Cho KS, Song TM, Lee CM, et al. Evaluation of Smoking Cessation Program at Public Health Center in 2004: Analysis on Key Factors and Rates in Smoking Cessation. J Health Info Stat 2006;31(1):35-49.

[8] World Health Organization [Internet]. WHO framework convention on tobacco control 2005. 2005 [cited 2014 Feb 21]. Available from: http:// whqlibdoc.who.int/publications/2003/9241591013.pdf.

[9] Koo SM, Kang JH. Factors affecting smoking cessation success during 4-week smoking cessation program for university students. J Korean Acad Community Health Nurs 2017;28(2):165-72.

[10] Ministry of Health and Welfare. Korea Health promotion Institute. National smoking cessation support center: manual for consultation at smoking cessation clinic in public health center in 2015. Sejong (Korea): Ministry Health and Welfare; 2015.

[11] Yeom H, Lim HS, Min J, et al. Factors Affecting Smoking Cessation Success of Heavy Smokers Registered in the Intensive Care Smoking Cessation Camp (Data from the National Tobacco Control Center) Osong Public Health Res Perspect 2018;9(5):240-7. 